\title{
SAMPLE PREPARATION OF DISSOLVED ORGANIC CARBON IN GROUNDWATER FOR AMS ${ }^{14} \mathrm{C}$ ANALYSIS
}

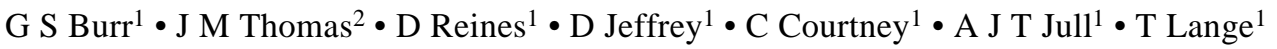

\begin{abstract}
This study describes a sample preparation technique used to isolate dissolved organic carbon (DOC) in groundwater for radiocarbon analysis using accelerator mass spectrometry (AMS). The goal of the work is to improve our ability to determine groundwater residence times based on ${ }^{14} \mathrm{C}$ measurements of the DOC fraction in groundwater. Water samples were collected from carbonate and volcanic rock aquifers in southern Nevada. Multiple measurements of total dissolved organic carbon (TDOC) in groundwater from one site are used to demonstrate the reproducibility of the analytical procedure. The reproducibility of the method is about one percent $(1 \sigma)$ for a $0.5 \mathrm{mg}$ sample. The procedural blank for the same size sample contains about 1 percent modern carbon (pMC).
\end{abstract}

\section{INTRODUCTION}

Determining groundwater residence time is an essential component in understanding the hydrodynamics of an aquifer system. This information is needed to plan for future well development, particularly in highly populated desert regions such as southern Nevada. Radiocarbon dating of groundwater is usually accomplished by measuring the ${ }^{14} \mathrm{C}$ content of the dissolved inorganic carbon (DIC) fraction and then correcting this ${ }^{14} \mathrm{C}$ value for geochemical reactions that add or remove carbon to the groundwater. For example, the computer program NETPATH (Plummer et al. 1994) can be used to model geochemical reactions that produce a ${ }^{14} \mathrm{C}$ dilution. Changes in ${ }^{14} \mathrm{C}$ resulting from geochemical reactions can be constrained by ${ }^{13} \mathrm{C}$ information from the same system. The difference between ${ }^{14} \mathrm{C}$ values corrected for geochemical reactions and measured ${ }^{14} \mathrm{C}$ in water along a flow path is assumed to be due to radioactive decay and this represents the time it takes groundwater to flow from one site to another. This residence time is the corrected DIC ${ }^{14} \mathrm{C}$ groundwater age.

In carbonate rock aquifers, the degree of ${ }^{14} \mathrm{C}$ dilution can be significant and variable, producing a wide range of DIC ${ }^{14} \mathrm{C}$ ages. For example, Plummer et al. (1990) and Thomas et al. (1996a) calculated model ${ }^{14} \mathrm{C}$ groundwater ages in carbonate rock aquifers in Montana and southern Nevada. These corrected values can reduce uncorrected ${ }^{14} \mathrm{C}$ ages of $20 \mathrm{ka}$ to less than $10 \mathrm{ka}$.

The dissolved organic carbon (DOC) fraction in groundwater is less susceptible to aquifer dilution and hence residence times determined from DOC ${ }^{14} \mathrm{C}$ measurements are potentially more accurate than those based on DIC measurements. Previous studies of DOC dating methods have been carried out by a number of researchers, including Murphy (1987), Murphy et al. (1989a, 1989b), Wassenaar et al. (1989), Drimmie et al. (1991), Wassenaar et al. (1991), Purdy et al. (1992), Aravena and Wassenaar (1993), Artinger et al. (1995), Aravena et al. (1995), and Ivanovich et al. (1996). In these studies, DOC dates were generally found to produce younger ages than the DIC fractions from the same water, consistent with the idea that the DOC fraction contains significantly less aquifer carbon. These studies also showed that certain DOC fractions appear to be relatively inert and probably provide the best means of determining the most realistic residence time estimates for the water. In a preliminary study, we determined that DOC ages from southern Nevada were consistently younger than apparent DIC ages from the same water, sometimes by thousands of years (Thomas 1996; Thomas et al. 1996a; Burr et al. 1996). It was also demonstrated that the DOC fraction with molecular masses in excess of 3000 amu provided the most reasonable age estimates for southern Nevada groundwaters.

\footnotetext{
${ }^{1}$ University of Arizona, NSF-Arizona AMS Laboratory, Tucson, Arizona 85721 USA. Email: Burr@u.arizona.edu. ${ }^{2}$ Desert Research Institute, 2215 Raggio Parkway, Reno, Nevada 89512, USA
}

(C) 2001 by the Arizona Board of Regents on behalf of the University of Arizona RADIOCARBON, Vol 43, Nr 2A, 2001, p 183-190

Proceedings of the 17 th International ${ }^{14} \mathrm{C}$ Conference, edited by I Carmi and E Boaretto 
Although DOC ${ }^{14} \mathrm{C}$ methods have been successfully applied to a number of environments, they have not found general applicability in hydrological studies. The purpose of this study is to develop a simplified method, which can be used in a wide range of hydrologic systems. The method should be suitable for large numbers of samples, less than a few liters in volume, with carbon concentrations as low as $100 \mu \mathrm{g} \mathrm{C} / \mathrm{L}$. This paper is concerned only with the separation of total organic carbon but the evaporation system described here can be combined with ultrafiltration to make ${ }^{14} \mathrm{C}$ measurements on selected molecular weight fractions of the TDOC (Crum et al. 1996).

\section{STUDY AREA}

All of the data presented in this report come from aquifers in southern Nevada (Figure 1). The aquifers are composed of fractured carbonate and volcanic rock. Groundwater flows mainly through fractures, which are generally lined with secondary calcite. The fracture flow systems include several topographic basins and pass beneath topographic divides before discharging at springs where the regional groundwater flow encounters flow barriers.

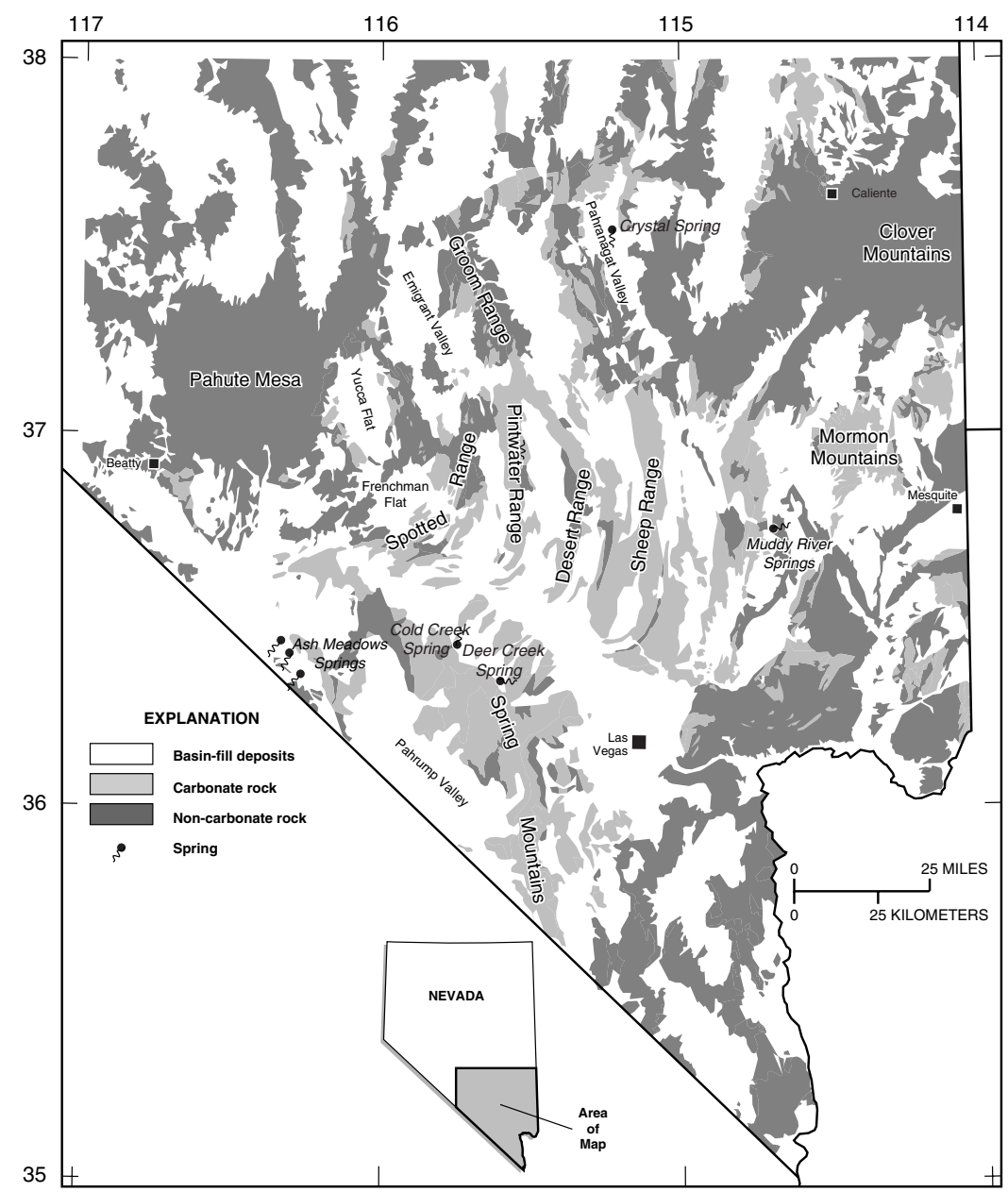

Figure 1 Map of study area—southern Nevada 


\section{METHODS}

\section{Sample Collection}

DOC and DIC samples for carbon isotope analyses were collected from the same 0.45 micron filter apparatus (a stainless steel filter housing with a polysulfone filter). The samples were collected in brown glass bottles that had been baked previously to $350{ }^{\circ} \mathrm{C}$. Samples were capped with no head space and shipped in a refrigerated container to the laboratory.

\section{DOC Extraction}

The general problem of extracting DOC from water for ${ }^{14} \mathrm{C}$ analysis is that it is time consuming and labor intensive. In addition, the generally small amounts of DOC found in groundwater mean that any sample pretreatment or handling procedure will be susceptible to carbon contamination. Our efforts here are directed at solving these two problems.

We tried a number of methods for isolating DOC from groundwater, including UV photo-oxidation, freeze-drying, evaporation in air, evaporation in nitrogen, and evaporation under a vacuum. For our earlier studies (Thomas 1996; Thomas et al. 1996b; Burr et al. 1996) we used freeze drying to isolate the DOC component. This posed two problems: 1) freeze-drying 1 liter of sample with our system required about five days, and 2) due to the long time required and the very tiny amounts of $\mathrm{C}$ in the samples (often $<100 \mu \mathrm{g}$ ), we experienced contamination from oil backstreaming during the freeze drying procedure. The oil originates in the rotary pump and slowly makes its way into the sample. Since the sample is frozen, it acts as a cryogenic trap. The longer the sample is exposed to the rotary pump, the more opportunity it has to incorporate oil. Evidence for oil backstreaming was observed in replicate analyses of samples with different masses. Replicate samples showed unacceptable variations (up to 20\%) in their measured ${ }^{14} \mathrm{C} /{ }^{13} \mathrm{C}$ ratios and variable $\delta^{13} \mathrm{C}$ values.

We chose to use evaporation to process our water samples instead of freeze drying because the evaporation technique eliminates the oil contamination problem. Evaporation has two significant advantages when compared to freeze drying. First, it is faster than freeze drying. The vapor pressure of liquid water at $60{ }^{\circ} \mathrm{C}$ is a factor of 40 higher than the vapor pressure over ice at the same temperature (Weast and Astle 1982). Thus, the water is removed more efficiently. Second, evaporation can be accomplished at a relatively higher pressure with a diaphragm (oil-free) pump, so that any possible oil backstreaming is eliminated.

We experimented with evaporation in air, but the samples became contaminated, incorporating atmospheric carbon during evaporation. Evaporation in nitrogen avoided this problem, as well as oil backstreaming, but the time to evaporate a sample was still too long-about five days for a 1 liter sample. Thus we constructed and refined a system to evaporate the samples under a vacuum, using an oil-free diaphragm pump (Figure 2). In this system, approximately 1 liter of sample is placed in the reaction vessel, acidified to a $\mathrm{pH}$ of less than 3 with phosphoric acid, and then placed under a vacuum. The phosphoric acid reacts with the DIC in the sample to form $\mathrm{CO}_{2}$, which is removed by the vacuum pump. This leaves only DOC, which is trapped in the salts produced during the evaporation. An important feature of the system is that the DOC fraction is never exposed to the atmosphere once the water is sealed in the reaction vessel. Once the sample is dried, it is detached from the evaporation apparatus under a vacuum, and moved to a separate vacuum line to be combusted. The combustion is performed by introducing oxygen gas into the reaction vessel and heating with a muffle furnace. The reaction vessels used in this study were fabricated from quartz to allow combustions up to $1000{ }^{\circ} \mathrm{C}$. We have found that we can extend the life of the quartz reaction vessels by sonicating them in an ultrasonic water bath after each use. 
Figure 2 Schematic of the evaporation system. The essential components of the system include a quartz reaction vessel where the sample can be evaporated and combusted. Once the sample is loaded into the quartz vessel, it is never exposed to the atmosphere. A second feature is an oilfree vacuum pump to eliminate potential contamination from oil backstreaming.

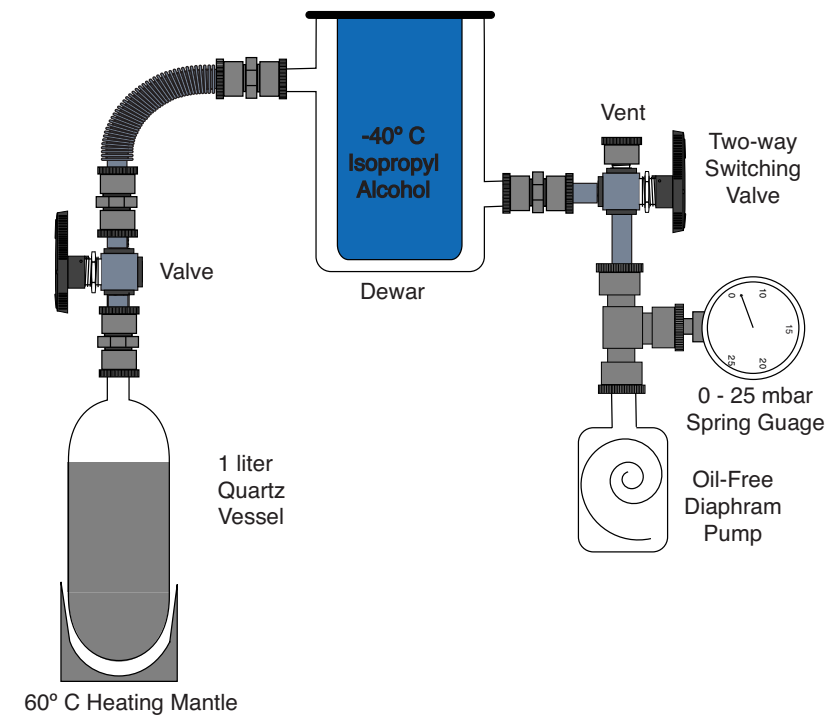

\section{Sulfur}

Freeze-drying or evaporation produces evaporites from the solutes in the groundwater and some of these are sulfates. Sulfates form $\mathrm{SO}_{2}$ when combusted. This poses a problem when calculating the $\mathrm{CO}_{2}$ combustion yield and the $\mathrm{SO}_{2}$ can poison the Fe catalysis step in the graphitization. Gas Chromatography analyses of some of our samples confirmed the presence of abundant $\mathrm{SO}_{2}$ in the combusted samples. Thus, a pentane + liquid nitrogen cryogenic trap $\left(-130^{\circ} \mathrm{C}\right)$ was added after the combustion step to remove $\mathrm{SO}_{2}$ by freezing.

\section{RESULTS AND DISCUSSION}

\section{Notation}

All of the results presented here are given as the fraction modern carbon $(F)$ value for the measurement. $\mathrm{F}$ is the defined as

$$
\mathrm{F}=\left({ }^{14} \mathrm{C} /{ }^{13} \mathrm{C}\right)_{\mathrm{s}} /\left({ }^{14} \mathrm{C} /{ }^{13} \mathrm{C}\right)_{\mathrm{STD}}
$$

where $\left({ }^{14} \mathrm{C} /{ }^{13} \mathrm{C}\right)_{\mathrm{S}}$ is the sample ratio, normalized to $\delta^{13} \mathrm{C}=-25 \%$ and $\left({ }^{14} \mathrm{C} /{ }^{13} \mathrm{C}\right)_{\mathrm{Std}}$ is the calculated standard ratio at 1950, determined from measurements of NBS oxalic acid standards, also normalized to $\delta^{13} \mathrm{C}=-25 \%$ o (Donahue et al. 1990).

\section{Standards}

Our first concern with the evaporation system was the potential for isotopic fractionation during sample processing. To determine whether the samples were fractionated we made ${ }^{14} \mathrm{C}$ measurements on two citric acid $\left(\mathrm{C}_{8} \mathrm{H}_{11} \mathrm{O}_{7}\right)$ standards. The fraction modern carbon values for these standards were about 1.75 and 1.35 . For both standards we made two measurements: 1 ) by direct combustion, and 2) by dissolving the standard in distilled water, evaporating until dry, and then combusting the salts. The ${ }^{14} \mathrm{C}$ results are shown in Figure 3. The agreement is within the expected uncertainties for the system and the data do not show any evidence for isotopic fractionation from the method. 


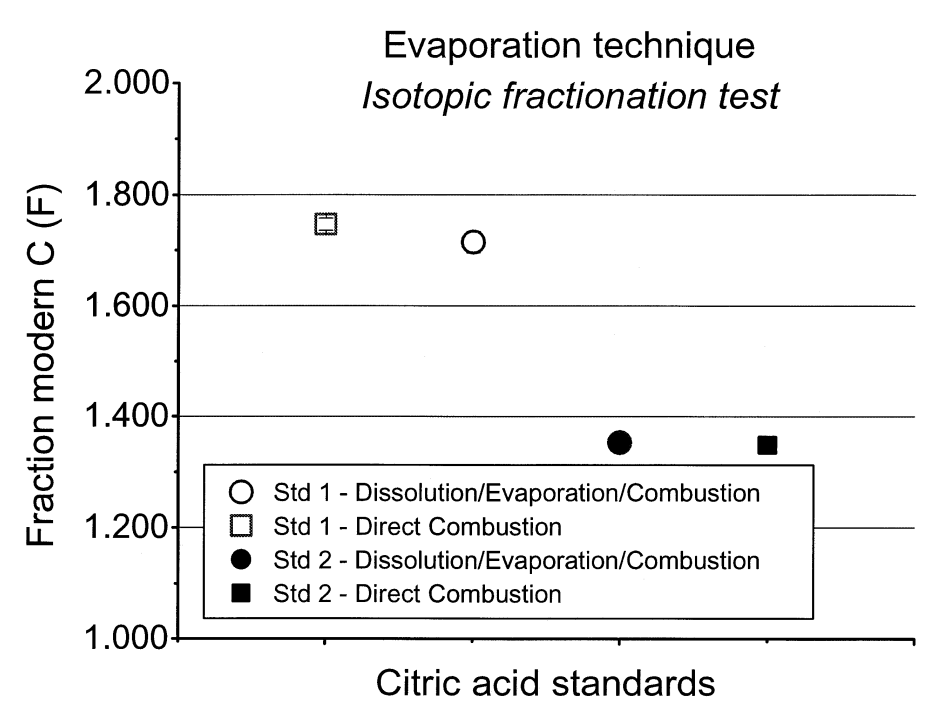

Figure 3 Fraction modern $\mathrm{C}$ values for two citric acid standards. Squares show results for citric acid standards that were combusted directly. Circles show results for samples which were processed with the evaporation system.

\section{Blanks}

Accurately assessing an analytical blank for groundwater samples is critical, given the very small sample sizes routinely used in our analyses. Concentrations in many of the groundwaters are $<100$ $\mu \mathrm{g} / \mathrm{L}$. We used ${ }^{14} \mathrm{C}$-depleted salicylic acid $\left(2-\mathrm{HOC}_{6} \mathrm{H}_{4} \mathrm{CO}_{2} \mathrm{H}\right)$ as our standard blank material. The salicylic acid was first combusted directly and determined to be comparable to our Iceland spar blank $(\mathrm{F}=0.004)$. Subsequent aliquots of salicylic acid were dissolved in distilled water and processed with our evaporation system. The results of these measurements are shown in Figure 4. Our first blank result had an $\mathrm{F}$ value of about 0.05 and the second result was about 0.03 . We modified the evaporation system by adding a valve to the end of the combustion vessel (as shown in Figure 2), which made it possible to keep the sample under a vacuum between the evaporation and combustion steps. As noted above, the sample is now isolated from the atmosphere once evaporation commences. This closed system approach lowered our procedural blank by an order of magnitude to $\mathrm{F}$ $\approx 0.005$, which is comparable with the blank for direct combustions.

\section{Reproducibility}

To test for the reproducibility of the system, seven replicate DOC measurements were made for a single sample site in the recharge zone of the Ash Meadows Flow System (Cold Creek Spring) in the Spring Mountains. The results of the measurements are shown in Figure 5. The average F value for this site is $0.939 \pm 0.011$, where the uncertainty expressed is the external variance of the population of measurements. The reproducibility of the system then is about $1 \%(1 \sigma)$. This level of precision is acceptable for the range of values observed in the study area. It is worth nothing that all of the values shown in Figure 5 were determined prior to the adoption of the closed system evaporation system and we expect the reproducibility of the closed system to improve on the current $1 \%$ value. 


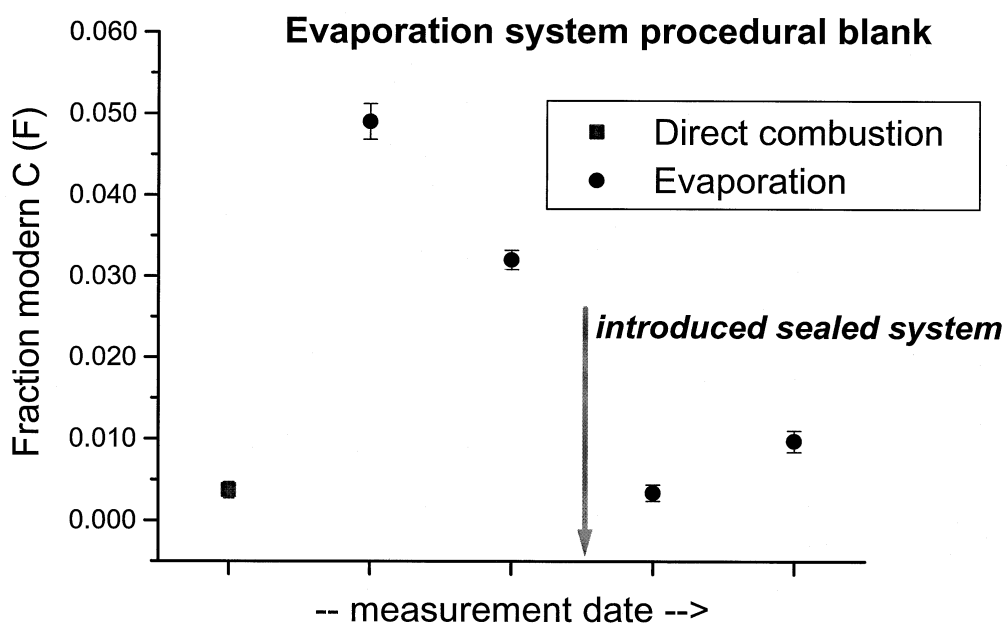

Figure 4 Fraction modern $\mathrm{C}$ values for the evaporation system procedural blank. Open square indicates the analytical blank as determined by direct combustion. Open circles show values for samples which were processed with the evaporation system in successive trials. Arrow indicates the introduction of closed system processing. In the closed system, the salts produced during evaporation are never exposed to the atmosphere.

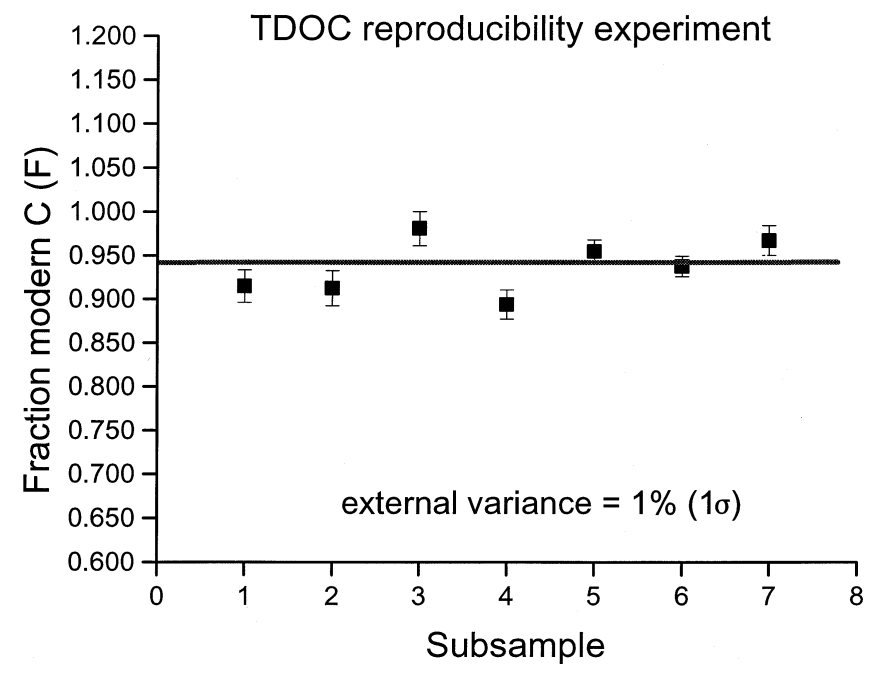

Figure 5 TDOC reproducibility experiment. Seven sample splits of water collected from Cold Creek Spring, southern Nevada. The values were determined after separate processing with the evaporation system. The samples were evaporated, combusted and reduced to graphite in consecutive experiments. The external variance of the population of points is about $1 \%$ and represents a measure of the reproducibility of the system. 


\section{Comparison Between Organic and Inorganic Carbon Fractions}

As stated above, it is generally known that the DIC fraction is more susceptible to aquifer dilution than the DOC fraction. Figure 6 shows this trend in 15 sites from southern Nevada. Only two of the DIC values exceed fraction modern carbon values of 0.5 . These sites are in recharge areas and contain tritium (Thomas et al. 1996a). Note that the rest of the DIC data show a relatively monotonous trend while corresponding DOC values demonstrate relatively large variability. This figure illustrates the potential advantages of deriving age information from DOC ${ }^{14} \mathrm{C}$ measurements as compared to DIC ${ }^{14} \mathrm{C}$ measurements.

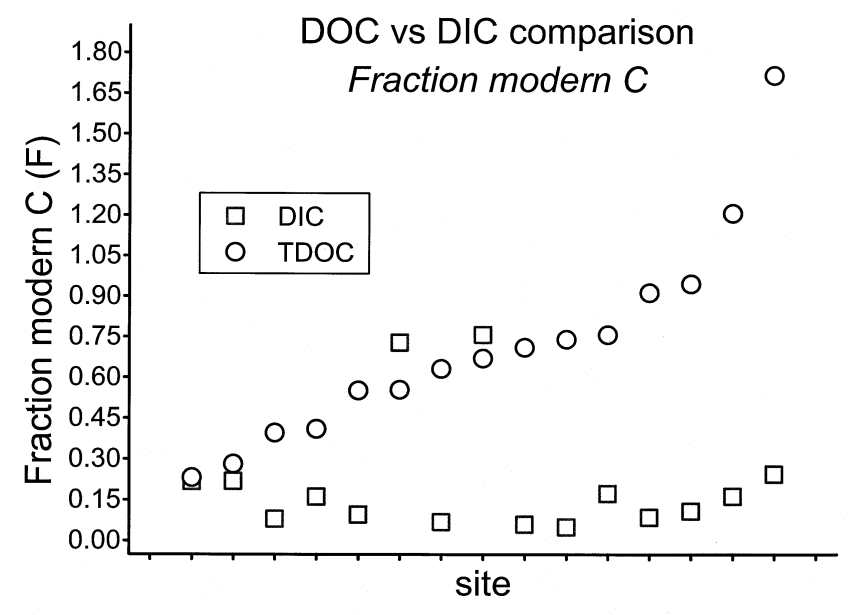

Figure 6 DIC vs. DOC results from 15 sample sites in southern Nevada. The ${ }^{14} \mathrm{C}$ content of DOC samples are much more variable than DIC fractions collected from the same wells. This is due to the relatively rapid and complete aquifer dilution effect in the DIC samples.

\section{CONCLUSIONS}

This study represents a first step in establishing a simple method for isolating DOC from groundwater samples for determination of ${ }^{14} \mathrm{C}$. The method described here has an external reproducibility of about $1 \%$ and an analytical blank of about $1 \mathrm{pMC}$ for a $0.5 \mathrm{mg}$ sample. The evaporation technique does not introduce significant isotopic fractionation during processing. It eliminates the problem of oil backstreaming observed in freeze-dried samples. The closed system approach eliminates atmospheric contamination and permits processing of very small samples $(<100 \mu \mathrm{g} \mathrm{C})$. We plan to use this technique to analyze individual DOC size fractions, isolated using ultrafiltration, in groundwaters from southern Nevada.

\section{ACKNOWLEDGMENTS}

We acknowledge the support for this project from the US Department of Energy and the National Science Foundation (EAR9730699). We thank Charlie Amling for fabricating the vacuum line and the quartz reaction vessels. We thank Dana Biddulph and Art Hatheway for assistance in the measurements. We also thank the two anonymous reviewers whose comments significantly improved the manuscript. 


\section{REFERENCES}

Aravena R, Wassenaar LI. 1993. Dissolved organic carbon and methane in a regional confined aquifer, southern Ontario, Canada: carbon isotope evidence for associated subsurface sources. Applied Geochemistry 8: 483-93.

Aravena R, Wassenaar LI, Plummer LN. 1995. Estimating ${ }^{14} \mathrm{C}$ groundwater ages in a methanogenic aquifer. Water Resources Research 31:2307-17.

Artinger R, Buckau G, Kim JI, Geyer S, Wolf M. 1995. The influence of sedimentary organic matter on dissolved fulvic acids in groundwater-significance for groundwater dating with ${ }^{14} \mathrm{C}$ in dissolved organic matter. International Symposium on Isotopes in Water Resources Management, IAEA. Vienna 336/26:1-15.

Burr GS, Thomas JM, Courtney C. 1996. Radiocarbon dating of dissolved organic and inorganic components in groundwater. Abstracts of the 7th International Accelerator Mass Spectrometry Conference. Radiocarbon 38(1):12.

Crum RH, Murphy EM, Keller CK. 1996. A non-adsorptive method for the isolation and fractionation of natural dissolved organic carbon. Water Research 30(5): 1304-11.

Donahue DJ, Linick TW, Jull AJT. 1990. Isotope-ratio and background corrections for accelerator mass spectrometry radiocarbon measurements. Radiocarbon 32(2): 135-42.

Drimmie RJ, Aravena R, Wassenaar LI, Fritz P, Hendry MJ, Hut G. 1991. Radiocarbon and stable isotopes in water and dissolved constituents, Milk River aquifer, Alberta, Canada. Applied Geochemistry 6:381-92.

Ivanovich M, Wolf M, Geyer S, Fritz P. 1996. Isotopic characterization of humic colloids and other organic and inorganic dissolved species in selected groundwaters from sand aquifers at Gorleben, Germany. American Chemical Society, Washington, D.C. Humic and Fulvic Acids, Special Publication 651:220-43.

Murphy EM. 1987. Carbon-14 measurements and characterization of dissolved organic carbon in ground water [PhD dissertation]. University of Arizona.

Murphy EM, Davis SN, Long A, Donahue DJ, Jull AJT. 1989a. Characterization and isotopic composition of organic and inorganic carbon in the Milk River aquifer. Water Resources Research 25:1893-1905.

Murphy EM, Davis SN, Long A, Donahue DJ, Jull AJT. 1989b. ${ }^{14} \mathrm{C}$ in fractions of dissolved organic carbon in ground water. Nature 337:153-5.

Plummer LN, Busby JF, Lee RW, Hanshaw BB. 1990. Geochemical modeling of the Madison aquifer in parts of Montana, Wyoming, and South Dakota. Water Resources Research 26:1981-2014.

Plummer LN, Prestemon EC, Parkhurst DL. 1994. An interactive code (NETPATH) for modeling net geochemical reactions along a flow path, version 2.0. U.S. Geological Survey Water Resources Invest. Rep. 94169:130 p.

Purdy CB, Burr GS, Rubin M, Helz GR, Mignerey AC. 1992. Dissolved organic and inorganic C-14 concentrations and ages for coastal-plain aquifers in southern Maryland. Radiocarbon 34(3):654-63.

Thomas JM. 1996. Geochemical and isotopic interpretation of groundwater flow, geochemical processes, and age dating of groundwater in the carbonate-rock aquifers of the southern Basin and Range [PhD dissertation]. University of Nevada, Reno. 135 p.

Thomas JM, Welch AH, Dettinger MD. 1996a. Geochemistry and isotope hydrology of representative aquifers in the Great Basin region of Nevada, Utah, and adjacent states. US Geological Survey Professional Paper 1409-C.100 p.

Thomas JM, Winograd IJ, Coplen TB. 1996b. Carbon-14 dating of groundwater in southern Nevada: three decades of surprises. Geological Society of America, Abstracts with Programs 28(7):A-197.

Wassenaar L, Aravena R, Hendry J, Fritz P. 1991. Radiocarbon in dissolved organic carbon, a possible groundwater dating method-case-studies from Western Canada. Water Resources Research 28(8):1975-86.

Wassenaar L, Aravena R, Fritz P. 1989. The geochemistry and evolution of natural organic solutes in groundwater. Radiocarbon 31(3):865-76.

Weast RC, Astle MJ. 1982. CRC handbook of chemistry and physics. 62nd Edition. Boca Raton, Florida: CRC Press. $2331 \mathrm{p}$. 